Bond University

Research Repository

\title{
COVID-19 and Social Isolation: A Case for Why Home-Based Resistance Training Is Needed to Maintain Musculoskeletal and Psychosocial Health for Older Adults
}

Marcos-Pardo, Pablo Jorge; Espeso-García, Alejandro; López-Vivancos, Abraham; Abelleira Lamela, Tomás; Keogh, Justin W L

Published in:

Journal of Aging and Physical Activity

DOI:

10.1123/japa.2020-0131

Licence:

Other

Link to output in Bond University research repository.

Recommended citation(APA):

Marcos-Pardo, P. J., Espeso-García, A., López-Vivancos, A., Abelleira Lamela, T., \& Keogh, J. W. L. (2021).

COVID-19 and Social Isolation: A Case for Why Home-Based Resistance Training Is Needed to Maintain

Musculoskeletal and Psychosocial Health for Older Adults. Journal of Aging and Physical Activity, 29(2), 353359. https://doi.org/10.1123/japa.2020-0131

\section{General rights}

Copyright and moral rights for the publications made accessible in the public portal are retained by the authors and/or other copyright owners and it is a condition of accessing publications that users recognise and abide by the legal requirements associated with these rights.

For more information, or if you believe that this document breaches copyright, please contact the Bond University research repository coordinator. 
1 COVID-19 and social isolation: a case for why home-based resistance training is needed to maintain

2 musculoskeletal and psychosocial health for older adults 
ABSTRACT

2 The Coronavirus disease (COVID-19) outbreak in China has become the world's leading health headline

3 and is causing major panic and public concerns. Public health guidelines in many countries are suggesting

4 people stay at home to avoid human-to-human transmission of the virus, which may lead to reduced

5 physical activity and greater feelings of isolation. Such effects may be particularly problematic in older

6 adults, due to their reduced physical capacities and their potential for increased mental health issues such

7 as anxiety and depression. A potential way to minimise many of these side effects of stay-at-home may be

8 progressive home-based resistance training. A simple way to provide progressive overload in home-based

9 resistance training may involve elastic resistance, which have been demonstrated to provide similar

10 benefits to traditional resistance training equipment typically found in gymnasiums. Recommendations on

11 how older adults can safely and effectively perform elastic resistance training at home is provided.

12 Key words: coronavirus, elastic resistance training, physical activity. 
1 The Coronavirus disease (COVID-19) outbreak in China has become the world's leading health

2 headline and is causing major panic and public concerns. On January 30, 2020, the World Health

3 Organization (WHO) declared that the new coronavirus outbreak is a public health emergency of

4 international concern (World Health Organization, n.d.). The virus has already had a direct impact on

5 millions of people around the world, posing a health threat of unknown magnitude at the global level. As

6 of March 26, 2020, the pandemic, one of the biggest health crises in recent years whose consequences are

7 still unpredictable, has spread to more than 170 countries, resulting in $\sim 470,000$ cases and more than

820,000 deaths. In Spain, the number of positive cases with COVID-19 exceeds 56,000, ranking it as the

9 second highest in Europe, with only Italy having a greater number of confirmed cases. Spain is also

10 currently ranked second in the world in terms of the number of confirmed deaths from coronavirus.

11 Specifically, Spain has already recorded 4,145 deaths, whereas China has had 3,293 confirmed deaths so

12 far. Italy, with at least 7,500, has already doubled the number (Ministerio de Sanidad del Gobierno de

13 España, 2020). Currently, there is no vaccine for the prevention or treatment of the disease caused by the

14 virus; its origins and the ultimate scope of this pandemic are unknown. The causes or mechanisms of

15 transmission, the incubation period, risk assessments and effective treatment or intervention options for

16 the virus are also currently poorly understood.

17 Health authorities in countries such as China, Italy, China, the United States, Australia and Spain,

18 among others, have advised the public to reduce travel, stay home and maintain social distancing when in

19 public as a basic means of limiting people's exposure to the virus. Unfortunately, travel restrictions and

20 directives against participation in outdoor activities, including sport, physical activity and regular

21 exercise, will inevitably disrupt the daily activities of tens of millions of people.

\section{Issues For Older Adults}

24 While containing the virus as quickly as possible is the urgent public health priority, there have been few

25 public health guidelines as to what people, especially older adults can or should do in terms of

26 maintaining their daily exercise or physical activity routines. This is a concern as a large percentage of

Accepted author manuscript version reprinted, by permission, from Journal of Aging and Physical Activity, 2021, Vol 29(2). https://doi.org/10.1123/japa.2020-0131 
1 adults and older people do not meet the global recommendations for physical activity, especially

2 resistance training needed to reduce morbidity and maintain functional capacity (Sun, Norman, \& While,

3 2013; Winett, Williams, \& Davy, 2009). Arguably, staying home, while a safe measure, may have

4 unintended negative consequences since such efforts to avoid human-to-human transmission of the virus

5 may lead to reduced physical activity (P. Chen et al., 2020). Long hours in the home may lead to

6 increased sedentary behaviour and inactivity or little physical activity, long periods of sitting and lying

7 down; all of which increases the risk of developing or exacerbating chronic diseases (Owen, Sparling,

8 Healy, Dunstan, \& Matthews, 2010). Staying at home can also be socially isolating, particular for older

9 adults who may already have a reduced network of friends than younger adults and children (Freedman \&

10 Nicolle, 2020; Santini et al., 2020). This isolation for older adults may exacerbate issues related to their

11 mental health, with increased levels of anxiety and depression the likely result (Freedman \& Nicolle,

12 2020; Santini et al., 2020).

14 As many older adults are already highly concerned about contracting COVID-19 and the serious adverse

15 events or even death that may result from contracting the virus, such self- isolation has the potential to

16 cause a host of psychosocial and physical harm. Aging is a complex process characterized by structural

17 and physiological changes in various systems of the human body that can compromise anthropometric

18 (e.g. muscle mass, regional adiposity) and neurovascular (muscle strength, motor control) variables, and

19 reduce the physical independence of the older adults (Chodzko-Zajko et al., 2009).

21 Aging is associated with a progressive decrease of muscle mass and a reduced capacity of the muscles to

22 produce strength and power, that ultimately result in a decline in the ability to perform a range of

23 functional tasks including standing up from a chair or walking, particularly upstairs or while carrying

24 additional handheld loads (Aagaard, Suetta, Caserotti, Magnusson, \& Kjær, 2010; Guizelini, de Aguiar,

25 Denadai, Caputo, \& Greco, 2018). The ability of the lower extremity muscles to generate force and

26 muscular power is a fundamental component for maintaining balance ( $\mathrm{Li}$ et al., 2018), with the 
1 assessment of the force-velocity ratio advocated to determine the maximum capacities of older adults to

2 produce force, speed and power (Marcos-Pardo, González-Hernández, García-Ramos, López-Vivancos,

3 \& Jiménez-Reyes, 2019). These age-related losses of muscle mass, strength and physical performance is

4 now referred to as the geriatric syndrome, sarcopenia (Cruz-Jentoft et al., 2019). These sarcopenia-related

5 changes may increase the risk of falls and fractures, which could contribute to the loss of independence

6 and the deterioration in the physical function and quality of life of older adults (Gadelha et al., 2018; Ma

7 et al., 2018; Trombetti et al., 2016).

8

9 This relative disability and increase in falls and falls related fracture may require additional healthcare

10 services and costs, with the available health care services and funding already stretched due to the

11 COVID-19 pandemic. In particular, public health programs need to ensure older adults can maintain their

12 levels of muscular strength so to minimize these major healthcare cost implications. Specifically, Pinedo-

13 Villanueva and colleagues, reported that each older adult with muscle weakness (defined as having

14 handgrip strength $<26 \mathrm{~kg}$ for men or $<16 \mathrm{~kg}$ for women) cost the UK healthcare system an additional

15 US\$ 3,372 at current exchange rates per year (Pinedo-Villanueva et al., 2019).

\section{Exercise Benefits For Older Adults}

18 One way to counteract the potential psychosocial and physical deterioration as well as increased

19 healthcare costs that may be associated with the reduced level of physical activity that may occur with

20 social distancing and stay-at-home policies currently being advocated by many governments is exercise

21 (Hetherington et al., 2019; Raafs et al., 2019), although in the current climate it is recommended that such

22 exercise is home-based. Exercise at home using various safe, simple, and easily implementable exercises

23 is well suited to avoid the airborne coronavirus and maintain fitness levels. Such forms of exercise may

24 include, but are not limited to, strengthening (resistance training) exercises, activities for balance and

25 control, cardiovascular, stretching exercises, or a combination of these (P. Chen et al., 2020). 
1 Resistance training is widely recommended to slow down the negative effects of aging in sarcopenia-

2 related decline because it is considered the most effective method for improving muscle mass, strength

3 and power which are key to counteract disability in older adults (Cadore et al., 2014; Chodzko-zajko,

4 2014; Marcos-Pardo, Orquin-Castrillón, et al., 2019). In addition, individuals undertaking resistance

5 training demonstrate an increased motivation and adherence to training (Kekäläinen et al., 2018; Marcos-

6 Pardo, Martínez-Rodríguez \& Gil-Arias, 2018). Due to the confined state of adults and older people, safe

7 and effective strategies for resistance training at home are needed.

9 Home resistance training with minimal supervision is a safe, effective and low-cost exercise

10 option for increasing muscle strength and functional capacity in healthy older adults, as well as

11 older subjects with a variety of health conditions that can overcome some of the common barriers to

12 exercise (Henwood et al., 2019). It is an attractive, viable and, from a public health perspective, a feasible

13 alternative to supervised resistance training in gymnasiums (Kis et al., 2019), which are now largely

14 unavailable due to the risk of spreading the virus to vulnerable older adults. Training with small overload

15 materials such as bottles or dumbbells available at home, as well as elastic resistance training are effective

16 resistance training materials and easy to use for this age group (Andersen et al., 2011; Jensen et al., 2014).

17 Elastic resistance exercises are often used during unsupervised home training, where the exercise

18 professional or instructional web-based video provides the patient with initial instruction on how to

19 perform the exercise. These instructions may focus on exercise prescription variables including loading,

20 range of motion, number of repetitions, sets, pauses between exercises, and proper starting position (Faber

21 et al., 2015).

22

23 The use of elastic resistance training during confinement has multiple advantages for training at home;

24 they are easy to use, can be adjusted to different loads, are less expensive and do not take up as much

25 space as dumbbells or specialized resistance training machines. Multiple studies have compared elastic

26 bands training to traditional free weights (e.g. dumbbells) based resistance training in terms of the muscle

Accepted author manuscript version reprinted, by permission, from Journal of Aging and Physical Activity, 2021, Vol 29(2). https://doi.org/10.1123/japa.2020-0131 
1 activation levels (Andersen et al., 2010; Colado et al., 2010; Melchiorri \& Rainoldi, 2011). These studies

2 generally demonstrated that exercise training with elastic resistance activates the agonists at a similar

3 level to that achieved with dumbbells or weight machines, suggesting that bands can be as effective in

4 improving strength and reducing muscle loss as more traditional resistance training tools. Such a is

5 viewpoint is supported by a number of training studies demonstrating similarity in training related

6 adaptations in middle-aged to older healthy adults to elastic and traditional resistance training (Lima et

7 al., 2018; Mikesky, Topp, Wigglesworth, Harsha, \& Edwards, 1994; Yasuda, Fukumura, Tomaru, \&

8 Nakajima, 2016).

9 Phychosocial Benefits of Resistance Exercise for Older Adults

10 The National Strength and Conditioning Association have recently released a Position Statement (Fragala

11 et al., 2019) outlining the physical and psychosocial benefits of resistance training for older adults. A

12 major psychosocial benefit is improved quality of life, which can be defined as the subjective view of an

13 individual about their general well-being and ability to participate in enjoyable life events (Dionigi, 2007;

14 Kekäläinen, Kokko, Sipilä, \& Walker, 2018; Pedersen et al., 2017). These improvements in older adults

15 quality of life with resistance training may reflect a range of other psychosocial benefits including

16 improved self-esteem/confidence (O’Connor, Herring, \& Caravalho, 2010), sense of coherence

17 (Kekäläinen, Kokko, Sipilä, et al., 2018) and sleep quality (O’Connor et al., 2010) as well as a reduction

18 in depression and/or anxiety (O’Connor et al., 2010; Tsutsumi, Don, Zaichkowsky, \& Delizonna, 1997).

19 It has even been reported that the improvements in depression that may be observed with resistance

20 training are similar in magnitude to standard pharmacotherapy interventions for older adults with

21 depression (Singh et al., 2005). Further, there is even evidence for some forms of resistance training to

22 improve older adults' cognitive function, with enhancements in executive function accompanied by

23 functional changes in the frontal lobe (Herold, Törpel, Schega, \& Müller, 2019). Such improvements in

24 cognitive function may even have the potential to offset some of the behavioural issues associated with

25 advanced age dementia (K. M. Chen, Kuo, Chang, Huang, \& Cheng, 2017).

Accepted author manuscript version reprinted, by permission, from Journal of Aging and Physical Activity, 2021, Vol 29(2). https://doi.org/10.1123/japa.2020-0131 
1 Therefore, exercise during quarantine can help to combat many of the physical and mental negative

2 consequences of the social isolation policies adopted in many countries due to the Covid-19 pandemic

3 (Jiménez-Pavón, Carbonell-Baeza, \& Lavie, 2020). The participation of older people in resistance training

4 programs can serve as a prophylactic to delay or prevent the appearance of biological aging. The physical

5 and psychological benefits have been demonstrated if we use a minimum dose of two days a week and 60

6 minutes of training (Fisher, Steele, Gentil, Giessing, \& Westcott, 2017).

\section{Home Elastic Resistance Training Recommendations}

9 Consistent with exercise guidelines for older adults (Fragala et al., 2019), it would be recommended that

10 older people perform elastic resistance training 2 to 3 days a week, with such sessions perhaps starting off

11 with a duration of 15 or 20 minutes, but progressing up to 45-60 minutes. In the first few training

12 sessions, the older adult should become familiar with the different movements, how the use of elastics or

13 other forms of resistance (e.g. additional household objects) increases the difficulty of the exercise and

14 become comfortable with the potential delayed onset muscle soreness that may occur for a few days post

15 exercise.

17 The muscle groups and movements to be trained should focus on movements that replicate many common 18 activities of daily living and involve the major trunk and limb muscle groups. These exercises should seek

19 to improve lower body muscle mass, strength and power as well as balance so that the older adult can

20 minimize their falls risk and maintain their independence in performing common activities such as the sit

21 to stand and walking, particularly up or down stairs or carrying additional loads such as groceries. Older

22 adults also need to maintain or improve upper body strength so that they can to continue to hold loads in

23 their hands, lift objects from lower to higher positions such as shelves and are able to get off the floor if

24 they experience a fall. Each elastic resistance training session should consist of a warm-up at the

25 beginning and general stretching at the end. In particular, we would recommend that the following

26 movements are performed with adequate resistance, elbow curl (A), squat (B), elbow extension (C), knee 
1 extension (D), chest press (E), leg press (F), shoulder overhead press (G), knee curl (H) and shoulder

2 seated row (I). An example of the execution of the elastic resistance training can be seen in Figure 1.

$4 \quad$ Insert Figure 1 about here

6 The resistance of the elastics training varies from brand to brand and differs in color. Each color offers a

7 different level of resistance to the practitioner. It is very important that for the safety and effectiveness of

8 the training, the practitioner must be familiar with the load (strength of the band), the range of motion

9 (ROM) including the starting and finish position, the number of repetitions per set, and the optimal speed

10 of execution. To control the intensity of exercise with elastic bands, it is advisable to use the Resistance

11 Intensity Scale for Exercise; RISE in older people (Colado, Furtado, Teixeira, Flandez, \& Naclerio,

12 2020). The RISE scale (see Figure 2) is a valid method for assessing the perceived exertion during

13 resistance exercises performed with elastic bands in older people that better discriminates between

14 medium and low intensities than the Exercise Scale of Perceived Exertion (OMNI-RES) scale in older

15 adults (Colado et al., 2012, 2018).

17 Insert Figure 2 about here

19 One way to perform the resistance training program that may also provide some cardiovascular health

20 benefit, which is also important with the potential for reduced opportunities for cardiovascular exercise

21 such as walking, is to perform the resistance training exercises in a circuit training format (Fritz et al.,

22 2018; Souza et al., 2019), The following recommendations for how the elastic resistance training

23 exercises may be performed, progressed and incorporated into a circuit format for older adults are based

24 on the literature (Colado et al., 2020; de Oliveira, Pereira Moro, Polito, Helena de Jesus, \& de Souza

25 Bezerra, 2020; Fritz et al., 2018; Krause et al., 2019; Osuka et al., 2019; Rieping et al., 2019; Silva et al.,

26 2018; Souza et al., 2019). An older adult with little resistance training experience may initially perform 1-

Accepted author manuscript version reprinted, by permission, from Journal of Aging and Physical Activity, 2021, Vol 29(2). https://doi.org/10.1123/japa.2020-0131 
12 series of the circuit, with a load that allows 12 to 15 repetitions per set at a low to moderate level effort

2 on the RISE. As each repetition should be performed under control, with a two second concentric (lifting

3 the weight) and two second eccentric (lowering the weight) phase, each set of an exercise may last up to

460 seconds. The older adult can increase the intensity of the exercises as assessed by the RISE increasing

5 towards a perception of hard level effort between the second and fourth week. After four weeks of

6 training, it is advisable to progressively increase the number of training series, ultimately looking to

7 perform three or four series of the exercise circuit. As the weeks go by, and the older adult adapts to the

8 load, he or she should optionally increase the repetitions or increase the load, in this case changing to

9 another elastic of greater resistance. For older adults with some resistance training experience, they can

10 start with a moderate intensity level, with a higher resistance elastic and perform 10 to 12 repetitions per

11 series, with a hard level of effort perception by performing three or four sets of training, progressing up to

12 three to four days a week.

14 Where possible, we recommend older adults seek some supervision from an exercise specialist, with

15 experience in working with older adults. Nowadays, a host of telehealth/video conferences can be

16 incorporated whereby these exercise specialists can support older adults safely and effectively perform

17 this home-based progressive resistance training sessions.

\section{Conclusions}

20 Following these recommendations can help during the confinement period to reduce the loss of muscle

21 mass and strength, control and/or reduce body weight, avoid the accumulation of fatty tissue and combat

22 the occurrence of or reduce existing chronic diseases in adults and older people. Home resistance training

23 using elastic materials is a beneficial and necessary option for the maintenance of musculoskeletal and

24 psychosocial health.

25

\section{Statement of conflict of interest}


1 There is no conflict of interest of any of the listed authors.

\section{Funding}

4 Current research on active aging of PJMP research group are supported by a grant from the Spanish

5 Ministry of Science, Innovation and Universities- RETOS I+d+i 2018 (RTC-2017-6145-1) and

6 the European Union's ERASMUS+SPORT programme (grant agreement: 603121-EPP-1-2018-1-ES-

7 SPO-SCP).

8

9 Acknowledgements

10 The authors would like to thank all the adults and older participants involved in their projects and their

11 university for their support of their studies on active aging. Special thanks to MPS for their disinterested

12 collaboration in being the image of the proposed exercises.

13

14 


\section{References}

2 Aagaard, P., Suetta, C., Caserotti, P., Magnusson, S. P., \& Kjær, M. (2010). Role of the nervous system in

Andersen, L. L., Andersen, C. H., Mortensen, O. S., Poulsen, O. M., Bjørnlund, I. B. T., \& Zebis, M. K. (2010). Muscle Activation and Perceived Loading During Rehabilitation Exercises: Comparison of Dumbbells and Elastic Resistance. Physical Therapy, 90(4), 538-549. https://doi.org/10.2522/ptj.20090167

Andersen, L. L., Saervoll, C. A., Mortensen, O. S., Poulsen, O. M., Hannerz, H., \& Zebis, M. K. (2011). Effectiveness of small daily amounts of progressive resistance training for frequent neck/shoulder pain: Randomised controlled trial. Pain, 152(2), 440-446. https://doi.org/10.1016/j.pain.2010.11.016

Cadore, E. L., Casas-Herrero, A., Zambom-Ferraresi, F., Idoate, F., Millor, N., Gómez, M., ... Izquierdo, M. (2014). Multicomponent exercises including muscle power training enhance muscle mass, power output, and functional outcomes in institutionalized frail nonagenarians. Age, 36(2), 773-785. https://doi.org/10.1007/s11357-013-9586-Z

Chen, K. M., Kuo, C. C., Chang, Y. H., Huang, H. T., \& Cheng, Y. Y. (2017). Resistance Band Exercises Reduce Depression and Behavioral Problems of Wheelchair-Bound Older Adults with Dementia: A Cluster-Randomized Controlled Trial. Journal of the American Geriatrics Society, 65(2), 356-363. https://doi.org/10.1111/jgs.14526

Chen, P., Mao, L., Nassis, G. P., Harmer, P., Ainsworth, B. E., \& Li, F. (2020, March 1). Wuhan coronavirus (2019-nCoV): The need to maintain regular physical activity while taking precautions. Journal of Sport and Health Science. Elsevier B.V. https://doi.org/10.1016/j.jshs.2020.02.001

Chodzko-zajko, W. J. (2014). Exercise and Physical Activity for Older Adults Phase One : Building Phase Two : Seeking Consensus. Human Kinetics Journals, 3(1), 101-106. 
https://doi.org/https://doi.org/10.1123/kr.2014-0043

Chodzko-Zajko, W. J., Proctor, D. N., Fiatarone Singh, M. A., Minson, C. T., Nigg, C. R., Salem, G. J., \& Skinner, J. S. (2009). Exercise and Physical Activity for Older Adults. Medicine \& Science in Sports \& Exercise, 41(7), 1510-1530. https://doi.org/10.1249/MSS.0b013e3181a0c95c

Colado, J. C., Furtado, G. E., Teixeira, A. M., Flandez, J., \& Naclerio, F. (2020). Concurrent and Construct Validation of a New Scale for Rating Perceived Exertion during Elastic Resistance Training in The Elderly. Journal of Sports Science \& Medicine, 19(1), 175-186. Retrieved from http://www.ncbi.nlm.nih.gov/pubmed/32132841

Colado, J. C., Garcia-Masso, X., Pellicer, M., Alakhdar, Y., Benavent, J., \& Cabeza-Ruiz, R. (2010). A comparison of elastic tubing and isotonic resistance exercises. International Journal of Sports Medicine, 31(11), 810-817. https://doi.org/10.1055/s-0030-1262808

Colado, J. C., Garcia-Masso, X., Triplett, T. N., Flandez, J., Borreani, S., \& Tella, V. (2012). Concurrent validation of the omniresistance exercise scale of perceived exertion with thera-band resistance bands. Journal of Strength and Conditioning Research, 26(11), 3018-3024. https://doi.org/10.1519/JSC.0b013e318245c0c9

Colado, J. C., Pedrosa, F. M., Juesas, A., Gargallo, P., Carrasco, J. J., Flandez, J., ... Naclerio, F. (2018).

Concurrent validation of the OMNI-Resistance Exercise Scale of perceived exertion with elastic bands in the elderly. Experimental Gerontology, 103(December), 11-16.

https://doi.org/10.1016/j.exger.2017.12.009

Cruz-Jentoft, A. J., Bahat, G., Bauer, J., Boirie, Y., Bruyère, O., Cederholm, T., ... Schols, J. (2019, January 1). Sarcopenia: Revised European consensus on definition and diagnosis. Age and Ageing. Oxford University Press. https://doi.org/10.1093/ageing/afy169

de Oliveira, S. N., Pereira Moro, A. R., Polito, M. D., Helena de Jesus, J., \& de Souza Bezerra, E. (2020). Effects of Concurrent Training with Elastic Tubes in Hypertensive Patients: A Blind Controlled Randomized Clinical Trial. Experimental Aging Research, 46(1), 68-82. https://doi.org/10.1080/0361073X.2019.1693030 
1 Dionigi, R. (2007). Resistance training and older adults' beliefs about psychological benefits: The importance of self-efficacy and social interaction. Journal of Sport and Exercise Psychology, 29(6), 723-746. https://doi.org/10.1123/jsep.29.6.723

Faber, M., Andersen, M. H., Sevel, C., Thorborg, K., Bandholm, T., \& Rathleff, M. (2015). The majority are not performing home-exercises correctly two weeks after their initial instruction-An assessorblinded study. PeerJ, 2015(7), e1102. https://doi.org/10.7717/peerj.1102

Fisher, J. P., Steele, J., Gentil, P., Giessing, J., \& Westcott, W. L. (2017, December 1). A minimal dose approach to resistance training for the older adult; the prophylactic for aging. Experimental Gerontology. Elsevier Inc. https://doi.org/10.1016/j.exger.2017.09.012

Fragala, M. S., Cadore, E. L., Dorgo, S., Izquierdo, M., Kraemer, W. J., Peterson, M. D., \& Ryan, E. D. (2019). Resistance Training for Older Adults: Position Statement From the National Strength and Conditioning Association. Journal of Strength and Conditioning Research, 33(8), 2019-2052. https://doi.org/10.1519/JSC.0000000000003230

Freedman, A., \& Nicolle, J. (2020). Social isolation and loneliness: the new geriatric giants: Approach for primary care. Canadian Family Physician Medecin de Famille Canadien, 66(3), 176-182. Retrieved from http://www.ncbi.nlm.nih.gov/pubmed/32165464

Fritz, N. B., Juesas, Á., Gargallo, P., Calatayud, J., Fernández-Garrido, J., Rogers, M. E., \& Colado, J. C. (2018). Positive Effects of a Short-Term Intense Elastic Resistance Training Program on Body Composition and Physical Functioning in Overweight Older Women. Biological Research for Nursing, 20(3), 321-334. https://doi.org/10.1177/1099800418757676

Gadelha, A. B., Neri, S. G. R., Oliveira, R. J. de, Bottaro, M., David, A. C. de, Vainshelboim, B., \& Lima, R. M. (2018). Severity of sarcopenia is associated with postural balance and risk of falls in community-dwelling older women. Experimental Aging Research, 00(00), 1-12. https://doi.org/10.1080/0361073X.2018.1449591

Guizelini, P., de Aguiar, R., Denadai, B., Caputo, F., \& Greco, C. (2018). Effect of resistance training on muscle strength and rate of force development in healthy older adults: A systematic review and 
meta-analysis. Experimental Gerontology, 102, 51-58. https://doi.org/10.1016/j.exger.2017.11.020

Henwood, T., Hetherington, S., Purss, M., Rouse, K., Morrow, J., \& Smith, M. (2019). Active@home: Investigating the value of a home care worker-led exercise program for older adults with complex care needs. Journal of Aging and Physical Activity, 27(2), 284-289. https://doi.org/10.1123/japa.2017-0443

Herold, F., Törpel, A., Schega, L., \& Müller, N. G. (2019, July 10). Functional and/or structural brain changes in response to resistance exercises and resistance training lead to cognitive improvements A systematic review. European Review of Aging and Physical Activity. BioMed Central Ltd. https://doi.org/10.1186/s11556-019-0217-2

Hetherington, S., Swinton, P., Henwood, T., Keogh, J., Gardiner, P., Tuckett, A., ... Comans, T. (2019). Progressive Resistance Plus Balance Training for Older Australians Receiving In-Home Care Services: Cost-Effectiveness Analyses Alongside the Muscling Up Against Disability SteppedWedge Randomized Control Trial. Journal of Aging and Physical Activity, 1-8. https://doi.org/10.1123/japa.2019-0085

Jensen, J., Hölmich, P., Bandholm, T., Zebis, M. K., Andersen, L. L., \& Thorborg, K. (2014). Eccentric strengthening effect of hip-adductor training with elastic bands in Soccer players: A randomised controlled trial. British Journal of Sports Medicine, 48(4), 332-338. https://doi.org/10.1136/bjsports-2012-091095

Jiménez-Pavón, D., Carbonell-Baeza, A., \& Lavie, C. J. (2020). Physical exercise as therapy to fight against the mental and physical consequences of COVID-19 quarantine: Special focus in older people. Progress in Cardiovascular Diseases. https://doi.org/10.1016/j.pcad.2020.03.009

Kekäläinen, T., Kokko, K., Sipilä, S., \& Walker, S. (2018). Effects of a 9-month resistance training intervention on quality of life, sense of coherence, and depressive symptoms in older adults: randomized controlled trial. Quality of Life Research, 27(2), 455-465. https://doi.org/10.1007/s11136-017-1733-z

Kekäläinen, T., Kokko, K., Tammelin, T., Sipilä, S., \& Walker, S. (2018). Motivational characteristics 
and resistance training in older adults: A randomized controlled trial and 1-year follow-up. Scandinavian Journal of Medicine and Science in Sports, 28(11), 2416-2426. https://doi.org/10.1111/sms.13236

Kis, O., Buch, A., Stern, N., \& Moran, D. S. (2019). Minimally supervised home-based resistance training and muscle function in older adults: A meta-analysis. Archives of Gerontology and Geriatrics, 84, 103909. https://doi.org/10.1016/j.archger.2019.103909

Krause, M., Crognale, D., Cogan, K., Contarelli, S., Egan, B., Newsholme, P., \& De Vito, G. (2019). The effects of a combined bodyweight-based and elastic bands resistance training, with or without protein supplementation, on muscle mass, signaling and heat shock response in healthy older people. Experimental Gerontology, 115, 104-113. https://doi.org/10.1016/j.exger.2018.12.004

Li, Z., Wang, X.-X., Liang, Y.-Y., Chen, S.-Y., Sheng, J., \& Ma, S.-J. (2018). Effects of the visualfeedback-based force platform training with functional electric stimulation on the balance and prevention of falls in older adults: a randomized controlled trial. PeerJ, 6, e4244. https://doi.org/10.7717/peerj.4244

Lima, F. F., Camillo, C. A., Gobbo, L. A., Trevisan, I. B., do Nascimento, W. B. B. M., Silva, B. S. de A., ... Ramos, E. M. C. (2018). Resistance training using low cost elastic tubing is equally effective to conventional weight machines in middle-aged to older healthy adults: A quasi-randomized controlled clinical trial. Journal of Sports Science and Medicine, 17(1), 153-160.

Ma, A., Sun, Y., Zhang, H., Zhong, F., Lin, S., Gao, T., \& Cai, J. (2018). Association between Sarcopenia and Metabolic Syndrome in Middle-Aged and Older Non-Obese Adults: A Systematic Review and Meta-Analysis. Nutrients, 10(3), 364. https://doi.org/10.3390/nu10030364

Marcos-Pardo, P. J., González-Hernández, J. M., García-Ramos, A., López-Vivancos, A., \& JiménezReyes, P. (2019). Movement velocity can be used to estimate the relative load during the bench press and leg press exercises in older women. PeerJ, 7, e7533. https://doi.org/10.7717/peerj.7533

Marcos-Pardo, P. J., Martínez-Rodríguez, A., \& Gil-Arias, A. (2018). Impact of a motivational resistancetraining programme on adherence and body composition in the elderly. Scientific Reports, $8(1), 1-$ 
11. https://doi.org/10.1038/s41598-018-19764-6

Marcos-Pardo, P. J., Orquin-Castrillón, F. J., Gea-García, G. M., Menayo-Antúnez, R., González-Gálvez, N., Vale, R. G. de S., \& Martínez-Rodríguez, A. (2019). Effects of a moderate-to-high intensity resistance circuit training on fat mass, functional capacity, muscular strength, and quality of life in elderly: A randomized controlled trial. Scientific Reports, 9(1), 7830. https://doi.org/10.1038/s41598-019-44329-6

Melchiorri, G., \& Rainoldi, A. (2011). Muscle fatigue induced by two different resistances: Elastic tubing versus weight machines. Journal of Electromyography and Kinesiology, 21(6), 954-959. https://doi.org/10.1016/j.jelekin.2011.07.015

Mikesky, A. E., Topp, R., Wigglesworth, J. K., Harsha, D. M., \& Edwards, J. E. (1994). Efficacy of a home-based training program for older adults using elastic tubing. European Journal of Applied Physiology and Occupational Physiology, 69(4), 316-320. https://doi.org/10.1007/bf00392037

Ministerio de Sanidad del Gobierno de España. (2020). Resumen de la situación y aportaciones de esta actualización. Retrieved from https://www.aemps.gob.es/

O’Connor, P. J., Herring, M. P., \& Caravalho, A. (2010). Mental Health Benefits of Strength Training in Adults. American Journal of Lifestyle Medicine, 4(5), 377-396. https://doi.org/10.1177/1559827610368771

Osuka, Y., Kojima, N., Wakaba, K., Miyauchi, D., Tanaka, K., \& Kim, H. (2019). Effects of resistance training and/or beta-hydroxy-beta-methylbutyrate supplementation on muscle mass, muscle strength and physical performance in older women with reduced muscle mass: Protocol for a randomised, double-blind, placebo-controlled trial. BMJ Open, 9(2). https://doi.org/10.1136/bmjopen-2018025723

Owen, N., Sparling, P. B., Healy, G. N., Dunstan, D. W., \& Matthews, C. E. (2010). Sedentary behavior: Emerging evidence for a new health risk. Mayo Clinic Proceedings. Elsevier Ltd. https://doi.org/10.4065/mcp.2010.0444

Pedersen, M. T., Vorup, J., Nistrup, A., Wikman, J. M., Alstrøm, J. M., Melcher, P. S., .. Bangsbo, J. 
(2017). Effect of team sports and resistance training on physical function, quality of life, and motivation in older adults. Scandinavian Journal of Medicine and Science in Sports, 27(8), 852864. https://doi.org/10.1111/sms. 12823

Pinedo-Villanueva, R., Westbury, L. D., Syddall, H. E., Sanchez-Santos, M. T., Dennison, E. M., Robinson, S. M., \& Cooper, C. (2019). Health Care Costs Associated With Muscle Weakness: A UK Population-Based Estimate. Calcified Tissue International, 104(2), 137-144. https://doi.org/10.1007/s00223-018-0478-1

Raafs, B. M., Karssemeijer, E. G. A., Van der Horst, L., Aaronson, J. A., Olde Rikkert, M. G. M., \& Kessels, R. P. C. (2019). Physical Exercise Training Improves Quality of Life in Healthy Older Adults: A Meta-Analysis. Journal of Aging and Physical Activity, 28(1), 81-93. https://doi.org/10.1123/japa.2018-0436

Rieping, T., Furtado, G. E., Letieri, R. V., Chupel, M. U., Colado, J. C., Hogervorst, E., ... Ferreira, J. P. (2019). Effects of Different Chair-Based Exercises on Salivary Biomarkers and Functional Autonomy in Institutionalized Older Women. Research Quarterly for Exercise and Sport, 90(1), 3645. https://doi.org/10.1080/02701367.2018.1563272

Santini, Z. I., Jose, P. E., York Cornwell, E., Koyanagi, A., Nielsen, L., Hinrichsen, C., ... Koushede, V. (2020). Social disconnectedness, perceived isolation, and symptoms of depression and anxiety among older Americans (NSHAP): a longitudinal mediation analysis. The Lancet. Public Health, 5(1), e62-e70. https://doi.org/10.1016/S2468-2667(19)30230-0

Silva, B. S. de A., Lira, F. S., Rossi, F. E., de Freitas, M. C., Freire, A. P. C. F., dos Santos, V. R., \& Gobbo, L. A. (2018). Elastic resistance training improved glycemic homeostasis, strength, and functionality in sarcopenic older adults: A pilot study. Journal of Exercise Rehabilitation, 14(6), 1085-1091. https://doi.org/10.12965/jer.1836412.206

Singh, N. A., Stavrinos, T. M., Scarbek, Y., Galambos, G., Liber, C., Singh, M. A. F., ... Hospital, B. (2005). A Randomized Controlled Trial of High Versus Low Intensity Weight Training Versus General Practitioner Care for Clinical Depression in Older Adults. Retrieved from 
https://academic.oup.com/biomedgerontology/article-abstract/60/6/768/2948012

Souza, D., Barbalho, M., Vieira, C. A., Martins, W. R., Cadore, E. L., \& Gentil, P. (2019). Minimal dose resistance training with elastic tubes promotes functional and cardiovascular benefits to older women. Experimental Gerontology, 115, 132-138. https://doi.org/10.1016/j.exger.2018.12.001

Sun, F., Norman, I. J., \& While, A. E. (2013). Physical activity in older people: A systematic review. BMC Public Health, 13(1), 449. https://doi.org/10.1186/1471-2458-13-449

Trombetti, A., Reid, K. F., Hars, M., Herrmann, F. R., Pasha, E., Phillips, E. M., \& Fielding, R. A. (2016). Age-associated declines in muscle mass, strength, power, and physical performance: impact on fear of falling and quality of life. Osteoporosis International, 27(2), 463-471. https://doi.org/10.1007/s00198-015-3236-5

Tsutsumi, T., Don, B. M., Zaichkowsky, L. D., \& Delizonna, L. L. (1997). Physical fitness and psychological benefits of strength training in community dwelling older adults. Applied Human Science: Journal of Physiological Anthropology, 16(6), 257-266. https://doi.org/10.2114/jpa.16.257

Winett, R. A., Williams, D. M., \& Davy, B. M. (2009, February). Initiating and maintaining resistance training in older adults: A social cognitive theory-based approach. British Journal of Sports Medicine. NIH Public Access. https://doi.org/10.1136/bjsm.2008.049361

World Health Organization. (n.d.). Statement on the second meeting of the International Health Regulations (2005) Emergency Committee regarding the outbreak of novel coronavirus (2019nCoV). Retrieved March 26, 2020, from https://www.who.int/news-room/detail/30-01-2020statement-on-the-second-meeting-of-the-international-health-regulations-(2005)-emergencycommittee-regarding-the-outbreak-of-novel-coronavirus-(2019-ncov)

Yasuda, T., Fukumura, K., Tomaru, T., \& Nakajima, T. (2016). Thigh muscle size and vascular function after blood flow-restricted elastic band training in older women. Oncotarget, 7(23), 33595-33607. https://doi.org/10.18632/oncotarget.9564 